\title{
PERIODATE OXIDATION OF PEG-600, AN ESSENTIAL PHARMACEUTICAL POLYMER
}

\author{
K. V. S. KOTESWARA RAO ${ }^{1}$, R. VENKATA NADH ${ }^{2}$, K. VENKATA RATNAM ${ }^{2}$
}

${ }^{1}$ Department of Chemistry, GVSM Government Degree College, Ulavapadu 523292, India, ${ }^{2}$ GITAM University-Bengaluru Campus, Karnataka 561203, India

Email: doctornadh@yahoo.co.in

Received: 15 Jun 2019, Revised and Accepted: 06 Aug 2019

\section{ABSTRACT}

Objective: To study the kinetics of periodate oxidation of polyethylene glycol-600 (PEG-600), a familiar non-toxic polymer used in pharmaceutical and other fields of industry.

Methods: Reactions were carried out in alkaline medium and measured the kinetics by iodometry. One oxygen atom loss or two electrons transfer was observed per each molecule of periodate i.e., the rate of reaction was measured periodate converts to iodate because the formed iodate species is unable to oxidize the substrate molecules.

Results: Based on log (a-x) versus t plots, order w. r. t. oxidant (periodate) is unity. Reactions were found to be independent of substrate (PEG-600) concentration. A decrease in rate with an increase in alkali concentration [ $\left.\mathrm{OH}^{-}\right]$was found and order was inverse fractional. Temperature dependence of reaction rate was studied and then calculated the corresponding Arrhenius parameters.

Conclusion: An appropriate rate law was proposed by considering the above experimental results.

Keywords: PEG-600, Alkaline medium, Periodate, Oxidation, Kinetics

(c) 2019 The Authors. Published by Innovare Academic Sciences Pvt Ltd. This is an open-access article under the CC BY license (http://creativecommons.org/licenses/by/4.0/) DOI: http://dx.doi.org/10.22159/ijap.2019v11i5.34591

\section{INTRODUCTION}

Liquid polyethylene glycols (PEG 200-600) are used in parenteral as well as oral liquids. Polyethylene glycols (PEGs) are utilized in various pharmaceutical preparations which are useful for different routes of administration including oral (capsule, tablet and solution) and intravenous (injection) [1]. In drug delivery systems, PEGs play a vital role [2]. PEGs (200 to 8,000,000) are widely applicable in cosmetics [3]. Toxic substances from the surface of burned skin can be removed by using liquid PEGs as antidotes [4]. PEGs exhibit good phase transfer features and excellent solvent properties which can be integrated into an effective integrated system (known as ABREaqueous biphasic reactive extraction) which enables separation of catalysts and/or reactants from products [5]. Mechanical properties of concrete are improved by the usage of polyethylene glycol as selfcuring agent $[6,7]$.

Among other PEGs, PEG-600 is widely used to understand the intestinal physiology in human beings as it has low toxicity and freely excreted along with urine [8]. It is also extensively useful in the preparation of ointment bases and as a food additive. PEG-600 is also used for the preparation of membranes from Cellulose Acetate [9]. PEG 600 acts as an excellent environment-friendly surfactant in combination with polysorbate 20 in inhibition of zinc composite corrosion in presence of alkaline medium [10]. PEG 600 is used during dyeability of fabric. The process improves fabric sustainability as PEG acts as a swelling agent [11].

Study of reaction rate constants is useful for investigation of reaction mechanism and to derivation of rate laws to explain the observations [12]. Literature collection shows that kinetics of oxidation reactions involving $\mathrm{N}$-halo oxidants [13-21] and inorganic oxidants [22, 23] were well studied. Similarly, researchers are interested in the study of oxidation of various substituted alcohols $[13,14,21]$ including polyethylene glycols and especially, ceric (IV) ions [24, 25] and Fenton [26-28] were the best used oxidants. Catalytic amounts of $\mathrm{Mn} / \mathrm{Ce}$ composite oxide direct the oxidation of PEG to a radical mechanism [29]. Similarly, the involvement of free radicals was proposed using Ce(IV) oxidant in sulphuric acid medium in spite of the incomplete understanding of mechanism [24]. Poly(oxyethylene)-dicarboxylic acids were resulted in high concentrations in the room temperature oxidation of PEGs by Jone's reagent $[30,31]$ proposed two different stages in the uncatalyzed oxidation of PEG by permanganate and also studied the Ruthenium (III) influence. As periodate oxidation of PEG-600 was not studied earlier, it was considered for the present study taking into consideration of its wide industrial and pharmaceutical usage.

\section{MATERIALS AND METHODS}

In the current study, all the chemicals used were analytical grade purity. Reaction kinetics were measured by iodometry [32, 33]. In the PEG-600 oxidation, one oxygen atom loss or two electrons transfer was observed per each molecule of potassium periodate $\left(\mathrm{KIO}_{4}\right)$ i.e., the rate of reaction was measured periodate converts to iodate because, the formed iodate species is unable to oxidize the substrate molecules. Further confirmed the same by conducting the experiments separately with iodate $[12,32,33]$.

\section{RESULTS AND DISCUSSION}

\section{Reaction orders of oxidant}

To understand the order of reaction w. r. t. [oxidant], periodate concentration was altered from 0.00025 to $0.002 \mathrm{M}$, whereas maintained the concentrations of other reactant at constant values (table 1). Graphs were drawn between $\log (\mathrm{a}-\mathrm{x})$ vs time (fig. 1). Linear curves were observed up to about $2 / 3^{\text {rd }}$ of the reaction. It indicates first order reactions w. r. t. [periodate]. In addition, confirmed the first order kinetics from almost constant reaction rate values in the range of studied oxidant concentration.

\section{Reaction orders of substrate and alkali}

Independence of reaction rate on [substrate] was observed because, reaction rates were almost constant by changing the concentration of PEG-600 in the range of 0.0025 to $0.1 \mathrm{M}$. In contrast, literature survey shows that a decrease in reaction rate with an increase in substrate concentration was noted in the oxidation of sugar alcohols by $\mathrm{KIO}_{4}$ in alkaline medium $[32,33]$. 
Table 1: Variation of [periodate] and rate constants

\begin{tabular}{|c|c|}
\hline Conc of periodate (M) & $k_{1} \times 10^{4}\left(\min ^{-1}\right)$ \\
\hline 0.00025 & 5.62 \\
\hline 0.0005 & 5.30 \\
\hline 0.001 & 5.16 \\
\hline 0.002 & 5.07 \\
\hline $\begin{array}{l}\text { Reaction conditions: } \\
{[\mathrm{PEG}-600]=0.025 \mathrm{M}}\end{array}$ & \\
\hline Temperature $=35^{\circ} \mathrm{C}\left[\mathrm{OH}^{-}\right]=0.1 \mathrm{M}$ & \\
\hline
\end{tabular}

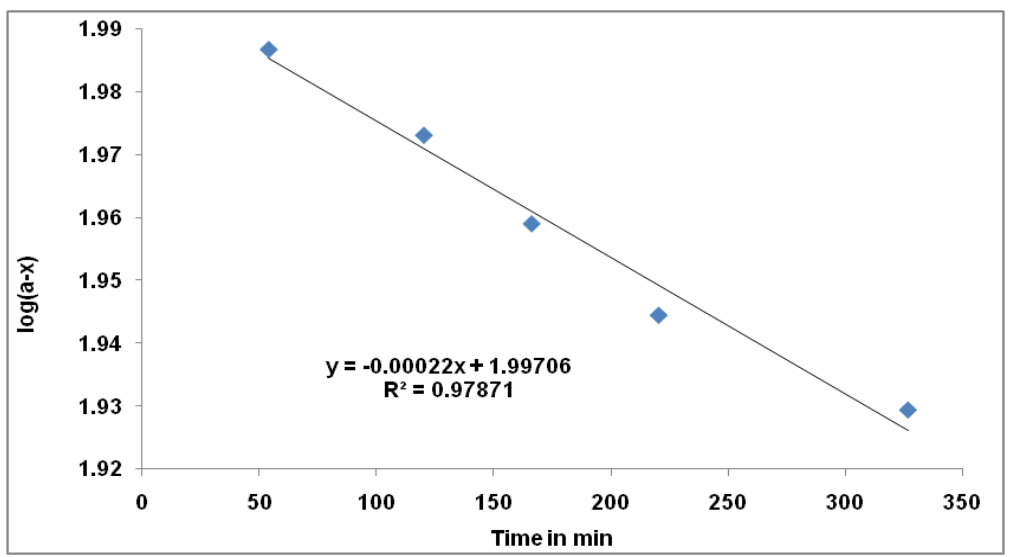

Fig. 1: Plot of $\log (\mathrm{a}-\mathrm{x})$ versus time at $\left[\mathrm{KIO}_{4}\right]=0.002 \mathrm{M},[\mathrm{PEG}-600]=0.025 \mathrm{M},\left[\mathrm{OH}^{-}\right]=0.1 \mathrm{M}$ and $\mathrm{Temperature}=35^{\circ} \mathrm{C}$

Table 2: Reaction rate variation with [PEG-600] and [alkali]

\begin{tabular}{|c|c|c|}
\hline Variant & Conc of variant (M) & $\mathrm{k}_{1} \times 10^{4} \mathrm{~min}^{-1}$ \\
\hline \multirow[t]{5}{*}{ [Substrate] } & 0.0025 & 5.43 \\
\hline & 0.0125 & 5.35 \\
\hline & 0.025 & 5.30 \\
\hline & 0.05 & 5.26 \\
\hline & 0.1 & 5.69 \\
\hline \multirow[t]{4}{*}{ [Alkali] } & 0.05 & 7.13 \\
\hline & 0.1 & 5.30 \\
\hline & 0.2 & 4.51 \\
\hline & 0.5 & 3.34 \\
\hline \multicolumn{3}{|c|}{$\begin{array}{l}\text { General reaction conditions: } \\
{\left[\text { PEG-600] }=0.025 \mathrm{M}\left[\mathrm{KIO}_{4}\right]=0.005 \mathrm{M}\right.} \\
\text { Temperature }=35^{\circ} \mathrm{C}\left[\mathrm{OH}^{-}\right]=0.1 \mathrm{M}\end{array}$} \\
\hline
\end{tabular}

Concentration of alkali was increased in the range of 0.05 to $0.5 \mathrm{M}$, where, reaction rate was decreased. A graph of log $\mathrm{k}_{1} \mathrm{vs} \log \left[\mathrm{OH}^{-}\right]$ shows a linear curve with a slope of-0.32 (fig. 2). It indicates the inverse fractional order of reaction in [alkali].

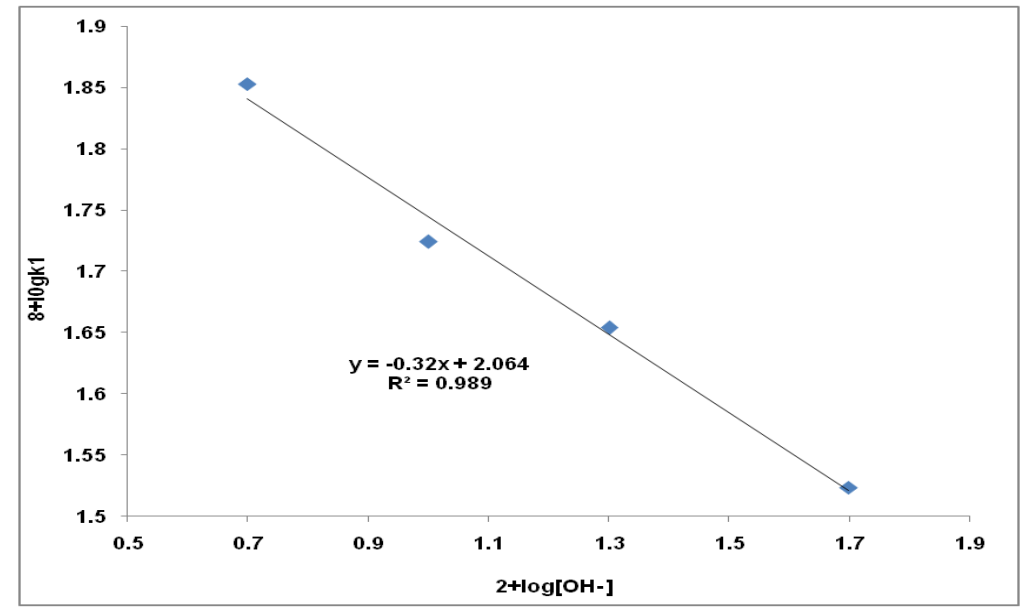

Fig. 2: Effect of alkali concentration on oxidation of PEG-600 by periodate 
Dissociation of potassium periodate takes place in alkaline medium [34] and results in establishment of equilibrium conditions between the products with those of reactants (1-3). The following equations show values of $K_{1}, K_{2}$ and $K_{3}$ (relevant equilibrium constants) which were shown at $298.2 \mathrm{~K}$.

$$
\begin{gathered}
2 \mathrm{IO}_{4}^{-}+2 \mathrm{OH}^{-} \rightleftharpoons \mathrm{H}_{2} \mathrm{I}_{2} \mathrm{O}_{10}^{4-} \log \mathrm{K}_{1}=15.05 \rightarrow(1) \\
\mathrm{IO}_{4}^{-}+\mathrm{OH}^{-}+\mathrm{H}_{2} \mathrm{O} \rightleftharpoons \mathrm{H}_{3} \mathrm{IO}_{6}^{2-} \log \mathrm{K}_{2}=6.21 \rightarrow(2) \\
\mathrm{IO}_{4}^{-}+2 \mathrm{OH}^{-} \rightleftharpoons \mathrm{H}_{2} \mathrm{IO}_{6}^{3-} \log \mathrm{K}_{3}=8.67 \rightarrow(3)
\end{gathered}
$$

The degree of existence of periodate species in aqueous alkaline medium can be calculated with the help of above equilibria. Out of the four species of periodate, concentrations of species- 1 and $2 \mathrm{O}_{4}^{-}$and $\mathrm{H}_{2} \mathrm{I}_{2} \mathrm{O}_{10}^{4-}$ are insignificant at the level of maintained hydroxide ion concentration. Hence, the available species at high concentrations are species- 3 and $4\left(\mathrm{H}_{2} \mathrm{IO}_{6}^{3-}\right.$ and $\left.\mathrm{H}_{3} \mathrm{IO}_{6}^{2-}\right)$, the concentrations of which can be determined with the support of
Crouthamel's data [35] (1951) in similar passion to others [3638]. Hence, the sum of concentration of these two active species $\left(\mathrm{H}_{3} \mathrm{IO}_{6}^{2-}\right.$ and $\left.\mathrm{H}_{2} \mathrm{IO}_{6}^{3-}\right)$ can be considered as equivalent to the overall periodate ion concentration which is denoted by $\left[\mathrm{IO}_{4}^{-}\right]_{\mathrm{ex}}$ The given below equations (4) and (5) were proposed by J. $\mathrm{H}$. Shan [39] based on the above equilibria (2) and (3).

$$
\begin{aligned}
& \mathrm{H}_{2} \mathrm{IO}_{6}^{3-}=\frac{\beta_{3}\left[\mathrm{OH}^{-}\right]^{2}}{1+\beta_{2}\left[\mathrm{OH}^{-}\right]+\beta_{3}\left[\mathrm{OH}^{-}\right]^{2}}\left[\mathrm{IO}_{4}^{-}\right]_{\mathrm{ex}}=\mathrm{f}\left(\left[\mathrm{OH}^{-}\right]\right)\left[\mathrm{IO}_{4}^{-}\right]_{\mathrm{ex}} \rightarrow(4) \\
& \mathrm{H}_{3} \mathrm{IO}_{6}^{2-}=\frac{\beta_{2}\left[\mathrm{OH}^{-}\right]}{1+\beta_{2}\left[\mathrm{OH}^{-}\right]+\beta_{3}\left[\mathrm{OH}^{-}\right]^{2}}\left[\mathrm{IO}_{4}^{-}\right]_{\mathrm{ex}}=\emptyset\left(\left[\mathrm{OH}^{-}\right]\right)\left[\mathrm{IO}_{4}^{-}\right]_{\mathrm{ex}} \rightarrow(5)
\end{aligned}
$$

Variation of concentrations of periodate species with concentration of alkali (fig. 3). A gradual increase in $\mathrm{H}_{2} \mathrm{IO}_{6}^{3-}$ concentration was observed with an increase in alkali concentration while a reverse phenomenon i.e., a gradual decrease in $\mathrm{H}_{3} \mathrm{IO}_{6}^{2-}$ concentration was noticed. So, these two species can complex with PEG-600.

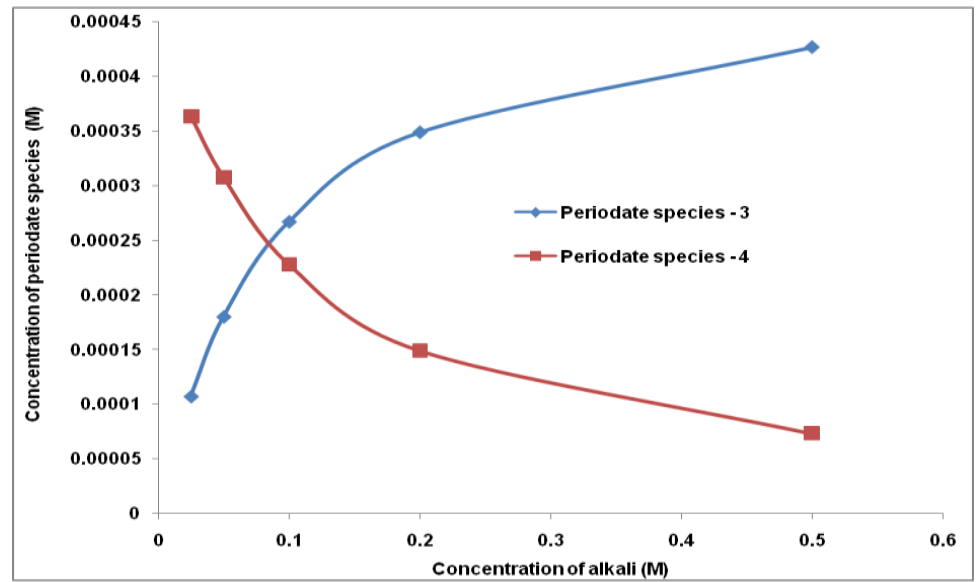

Fig. 3: Variation of concentrations of periodate species with different concentrations of alkali

\section{Temperature effect}

First-order rate constants $\left(\mathrm{k}_{1}\right)$ were measured at different concentrations from 35 to $50{ }^{\circ} \mathrm{C}$, where an increase in rate constant was observed with an increase in temperature. $\log \left(\mathrm{k}_{1}\right)$ was plotted against $1 / \mathrm{T}$ to give a straight line (fig. 4). Thermodynamic parameters were determined using Eyring equation and slope of the plot [40]. Tabulated the values of activation parameters $\left(\Delta \mathbf{E}^{\neq}, \Delta \mathbf{H}^{\neq}\right.$, $\Delta \mathbf{G}^{\neq}$and $-\Delta \mathbf{S}^{\neq}$) (table 3).

Table 3: Arrhenius parameters at $308 \mathrm{~K}$

\begin{tabular}{lllll}
\hline$\Delta \mathbf{E}^{\mp} \mathbf{K J} / \mathbf{m o l e}$ & $\Delta \mathbf{H}^{\mp} \mathbf{K J} / \mathbf{m o l e}$ & $-\Delta \mathbf{S}^{\mp} \mathbf{J K}^{-1} / \mathbf{m o l e}$ & $\log _{\mathbf{1 0}} \mathbf{P z}_{\mathbf{z}}$ & $\Delta \mathbf{G}^{\ddagger} \mathbf{K J} / \mathbf{m o l e}$ \\
\hline 79.25 & 76.69 & 93.00 & 8.38 & 105.33 \\
\hline
\end{tabular}

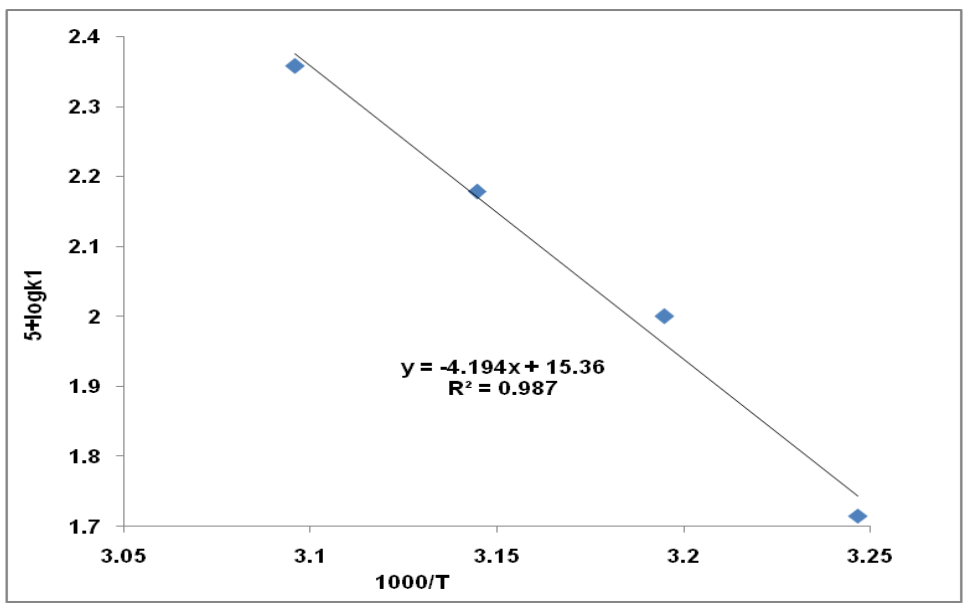

Fig. 4: Dependence of reaction rate on temperature variation 


\section{Boric acid and salts effect}

Literature survey indicates an improvement of reaction rate in alkali medium by the addition of boric acid in the periodateoxidation of different sugar alcohols [32, 33]. It was due to the favoured conditions to complex the sugar alcohols with borate ion. So, it gives a competition to form a stable complex of periodate with sugar alcohols. Hence, explained the observed substrate inhibition in such cases. However, in this study, no much alteration in reaction rate was observed after boric acid addition (table 4). It might be due to good number of hydroxyl groups in view of reasonable hydoxyl value of [41] PEG-600 in the range of 178-197. So, inspite of complexing of greatly ionisable potassium borate with certain-OH groups on PEG-600, the balance free hydroxyl groups number on substrate is also substantially high. Doubling of reaction rate was observed with the addition of bromide ions while, rate was retarded by the inclusion of chloride or iodide ions.

Table 4: Reaction rate variation with [salt] and [boric acid]

\begin{tabular}{|c|c|c|}
\hline Variant & Nature of Variant/Variant Conc (M) & $\mathrm{k}_{1} \times \mathbf{1 0}^{4} \mathrm{~min}^{-1}$ \\
\hline \multirow[t]{5}{*}{ Salt } & 0 & 5.30 \\
\hline & $\mathrm{KCl}$ & 3.72 \\
\hline & $\mathrm{KBr}$ & 13.27 \\
\hline & KI & 1.78 \\
\hline & $\mathrm{KNO}_{3}$ & 5.29 \\
\hline \multirow[t]{4}{*}{ [Boric Acid] } & 0 & 5.30 \\
\hline & 0.01 & 4.91 \\
\hline & 0.025 & 5.33 \\
\hline & 0.05 & 5.51 \\
\hline \multicolumn{3}{|c|}{$\begin{array}{l}\text { General Reaction Conditions: } \\
{[\mathrm{PEG}-600]=0.025 \mathrm{M}\left[\mathrm{KIO}_{4}\right]=0.005 \mathrm{M}}\end{array}$} \\
\hline \multicolumn{3}{|c|}{$\begin{array}{l}\text { Temperature }=35^{\circ} \mathrm{C}\left[\mathrm{OH}^{-}\right]=0.1 \mathrm{M} \\
{[\text { Salt }]=0.1 \mathrm{M}}\end{array}$} \\
\hline
\end{tabular}

\section{Rate law of equation}

The principal reaction products in the present study were long chain aldehydes along with a negligible extent of carboxylic acids in view of thorough oxidation. The nature of final products was identified using spot tests [42]. Conversion to 2,4dinitrophenyldrazones further established the formation of aldehydes. Nature of products are in the same order that reported by Szymański JK et al. [24]. Though the technical name of these substrates is 'polyethylene oxides', but commonly called as polyethylene glycols because the terminal-OH groups present on these displayan ample effect on physical properties and also on chemical properties [43]. Besides to it, hydroxyl value is also reasonably high. Hence, the oxidation of terminal hydroxyl groups resulted in the products noticed. Difficulty was faced while recording the precise stoichiometry. Suggested a rate law taking into consideration of the above kinetic orders.

As discussed above, available species in reasonable quantities are $\mathrm{H}_{2} \mathrm{IO}_{6}^{3-}$ and $\mathrm{H}_{3} \mathrm{IO}_{6}^{2-}$. They form complexes $\mathrm{C} 1$ and $\mathrm{C} 2$ respectively with the substrate (PEG-600), which dissociate at slower rate to form products.

$$
\begin{aligned}
& \mathrm{H}_{3} \mathrm{IO}_{6}^{2-}+\mathrm{S} \stackrel{\mathrm{K}_{4}}{\rightleftharpoons} \text { Complex } \mathrm{C}_{1} \stackrel{\mathrm{K}_{1}}{\longrightarrow} \text { Products } \\
& \mathrm{H}_{2} \mathrm{OO}_{6}^{3-}+\mathrm{S} \stackrel{\mathrm{K}_{5}}{\rightleftharpoons} \text { Complex } \mathrm{C}_{2} \stackrel{\mathrm{K}_{2}}{\longrightarrow} \text { Products }
\end{aligned}
$$

We know that $\left[\mathrm{IO}_{4}^{-}\right]_{\mathrm{T}}=\left[\mathrm{IO}_{4}^{-}\right]+\left[\mathrm{H}_{2} \mathrm{I}_{2} \mathrm{O}_{10^{4-}}\right]+\left[\mathrm{H}_{3} \mathrm{IO}_{6}{ }^{2-}\right]+\left[\mathrm{H}_{2} \mathrm{IO}_{6}{ }^{3-}\right.$ ]$+\left[\right.$ Complex $\left.\mathrm{C}_{1}\right]+\left[\right.$ Complex $\left._{2}\right]$

Where $\left[\mathrm{IO}_{4}{ }^{-}\right]_{\mathrm{T}}$ represents the total concentration of periodate and it can be rewritten as given below by taking into consideration of $\left[\mathrm{IO}_{4}^{-}\right.$ ] and $\left[\mathrm{H}_{2} \mathrm{I}_{2} \mathrm{O}_{10^{4-}}\right]$ as negligible.

$\left[\mathrm{IO}_{4}^{-}\right]_{\mathrm{T}}=\left[\mathrm{H}_{3} \mathrm{IO}_{6}^{2-}\right]+\left[\mathrm{H}_{2} \mathrm{IO}_{6}^{3-}\right]+\left[\right.$ Complex $\left.\mathrm{C}_{1}\right]+\left[\right.$ Complex $\left.\mathrm{C}_{2}\right]$

$=\mathrm{K}_{2}[\mathrm{IO}-\overline{4}]\left[\mathrm{OH}^{-}\right]+\mathrm{K}_{3}\left[\mathrm{IO}-\overline{4}\left[\mathrm{OH}^{-}\right]^{2}\right.$

$+K_{2} K_{4}[\mathrm{~S}]\left[\mathrm{IO}_{4}^{-}\right]\left[\mathrm{OH}^{-}\right]+K_{3} K_{5}[\mathrm{~S}]\left[\mathrm{IO}_{4}^{-}\right]\left[\mathrm{OH}^{-}\right]^{2}$

We can presume the non-availability of any uncomplexed periodate ions $\left(\mathrm{H}_{3} \mathrm{IO}_{6}^{2-}\right.$ and $\left.\mathrm{H}_{2} \mathrm{IO}_{6}^{3-}\right)$ because they are totally complexed with$\mathrm{OH}$ groups present on substrate molecules in view of large number of hydroxyl groups in the range [41] of 178-197. Hence, the above equation can be rewritten as given below by omitting the negligible quantities $\left(\mathrm{H}_{3} \mathrm{IO}_{6}^{2-}\right.$ and $\left.\mathrm{H}_{2} \mathrm{I}_{6}^{3-}\right)$.

$$
\begin{aligned}
& {\left[\mathrm{IO}_{4}^{-}\right]_{\mathrm{T}}=K_{2} K_{4}[\mathrm{~S}]\left[\mathrm{IO}_{4}^{-}\right]\left[\mathrm{OH}^{-}\right]+K_{3} K_{5}[\mathrm{~S}]\left[\mathrm{IO}_{4}^{-}\right]\left[\mathrm{OH}^{-}\right]^{2}} \\
& \text { Rate }=k_{1}\left[\text { Complex } C_{1}\right]+k_{2}\left[\text { Complex } C_{2}\right] \\
& =k_{1} K_{4}\left[\mathrm{H}_{3} \mathrm{I} O_{6}^{2-}\right][\mathrm{S}]+k_{2} K_{5}\left[\mathrm{H}_{2} \mathrm{I} O_{6}^{3-}\right][\mathrm{S}] \\
& =k_{1} K_{2} K_{4}\left[\mathrm{IO}_{4}^{-}\right]\left[\mathrm{OH}^{-}\right][\mathrm{S}]+k_{2} K_{3} K_{5}\left[\mathrm{IO}_{4}^{-}\right]\left[\mathrm{OH}^{-}\right]^{2}[\mathrm{~S}] \\
& =\left[\mathrm{IO}_{4}^{-}\right]\left[\mathrm{OH}^{-}\right][\mathrm{S}]\left\{k_{1} K_{2} K_{4}+k_{2} K_{3} K_{5}\left[\mathrm{OH}^{-}\right]\right\} \\
& =\frac{\left[\mathrm{IO}_{4}^{-}\right]_{\mathrm{T}}[\mathrm{S}]\left\{k_{1} K_{2} K_{4}+k_{2} K_{3} K_{5}\left[\mathrm{OH}^{-}\right]\right\}}{[\mathrm{S}]\left\{K_{2} K_{4}+K_{3} K_{5}\left[\mathrm{OH}^{-}\right]\right.} \\
& =\frac{\left[\mathrm{IO}_{4}^{-}\right]_{\mathrm{T}}\left\{k_{1} K_{2} K_{4}+k_{2} K_{3} K_{5}\left[\mathrm{OH}^{-}\right]\right\}}{\left\{K_{2} K_{4}+K_{3} K_{5}\left[\mathrm{OH}^{-}\right]\right.}
\end{aligned}
$$

First order reaction in [oxidant] and zero order in [S] are explained by the above rate law. Value of $\mathrm{k} 2$ is very less than unity and hence, hydroxide concentration is very small than that of value in denominator. Henceforth, inverse fractional order in [OH-] is explained.

In view of the present focus of research on applications of natural polymers in pharmaceutical and other fields [44-46], the outcome of the present study help to understand the stability of familiar nontoxic polymer (PEG-600) in presence of periodate in alkaline medium.

\section{CONCLUSION}

An appropriate rate law was proposed for the periodate oxidation of PEG-600, a pharmaceutical polymer in alkaline medium. Long chain aldehydes were the prime final product with insignificant degree of carboxylic acids. The present study helps to understand the stability of the polymer.

\section{ACKNOWLEDGEMENT}

KVSK is thankful to UGC-New Delhi for financial support in the form of Minor Research Project, F. No.4-4/2015-15(MRP-SEM/UGCSERO), November 2014

\section{AUTHORS CONTRIBUTIONS}

All the authors have contributed equally

\section{CONFLICT OF INTERSTS}

Declared none 


\section{REFERENCES}

1. D'souza AA, Shegokar R. Polyethylene glycol (PEG): a versatile polymer for pharmaceutical applications. Expert Opin Drug Delivery 2016;13:1257-75.

2. Kolate A, Baradia D, Patil S, Vhora I, Kore G, Misra A. PEG-a versatile conjugating ligand for drugs and drug delivery systems. J Controlled Release 2014;192:67-81.

3. Thomas A, Müller SS, Frey H. Beyond poly (ethylene glycol): Linear polyglycerol as a multifunctional polyether for biomedical and pharmaceutical applications. Biomacromolecules 2014;15:1935-54.

4. Cartotto RC, Peters WJ, Neligan PC, Douglas LG, Beeston J. Chemical burns. Can J Surg 1996;39:205.

5. Chen J, Spear SK, Huddleston JG, Rogers RD. Polyethylene glycol and solutions of polyethylene glycol as green reaction media. Green Chem 2005;7:64-82.

6. Venkateswarlu M, Balaji V, Susmitha M, Suresh D. Study on durability characteristics of conventional concrete with PEG600 as self curing compound. Eur J Adv Eng Technol 2015;2:47-52.

7. Lidiya, Preethi M. Mechanical properties of self curing concrete incorporating polyethylene glycol-600. Int Res J Eng Technol 2018;5:584-9.

8. Kinahan IM, Smyth MR. High-performance liquid chromatographic determination of PEG 600 in human urine. J Chromatogr B: Biomed Sci Appl 1991;565:297-307.

9. Cerqueira DA, Rodrigues Filho G, de Assuncao RM, da Silva Meireles C, Toledo LC, Zeni M, Mello K, et al. Characterization of cellulose triacetate membranes, produced from sugarcane bagasse, using PEG 600 as additive. Polym Bull 2008;60:397-404.

10. Liang M, Zhou H, Huang Q, Hu S, Li W. Synergistic effect of polyethylene glycol 600 and polysorbate 20 on corrosion inhibition of zinc anode in alkaline batteries. J Appl Electrochem 2011;41:991-7.

11. Chattopadhyay DP, Sharma JK, Patra AK. Effect of crosslinking in presence of PEG 600 on dyeability of cotton. Indian J Fibre Text Res 1997;22:124-9.

12. Laidler KJ. Text book of chemical kinetics. $3^{\text {rd }}$ Ed. Pearson Education Company, Singapore; 2004.

13. Venkata Nadh R, Syama Sundar B, Radhakrishnamurti PS. Kinetics of ruthenium (III) catalyzed and uncatalyzed oxidation of monoethanolamine by N-bromosuccinimide. Russ J Phys Chem A 2016;90:1760-5.

14. Nadh RV, Sundar BS, Radhakrishnamurti PS. Kinetics and mechanism of ruthenium (III) catalysed and uncatalysed oxidation of ethylamine and benzylamine by Nbromosuccinimide. Oxid Commun 2005;28:81-9.

15. Kumar YL, Nadh RV, Radhakrishnamurti PS. Shift of reaction pathway by added chloride ions in the oxidation of aromatic ketones by dichloroisocyanuric acid-a kinetic study. Russ J Phys Chem A 2016;90:552-9.

16. Kumar YL, Nadh RV, Radhakrishnamurti PS. Ruthenium (III) catalyzed oxidation of sugar alcohols by dichloroisocyanuric acid-a kinetic study. Russ J Phys Chem A 2016;90:300-7.

17. Kumar YL, Nadh RV, Radhakrishnamurti PS. Role of added chloride ions in alteration of reaction pathway in the oxidation of cyclic ketones by dichloroisocyanuric acid-a kinetic study. Russ J Phys Chem A 2015;89:376-83.

18. Kumar YL, Nadh RV, Radhakrishnamurti PS. Reactions of enolisable ketones with dichloroisocyanuric acid in absence and presence of added chloride ions-a kinetic study. Bull Chem Soc Ethiop 2015;29:129-36.

19. Venkata Nadh R, Syama Sundar B, Radhakrishnamurti PS. Kinetics of oxidation of aniline, p-aminobenzoic acid, and pnitroaniline by 2, 6-dichloroquinone-4-chloro-imide. Russ J Phys Chem A 2001;75:174-8.

20. Neeraja V, Venakata Nadh R, Syama Sundar B, Radhakrishnamurti PS. Kinetic studies of thiocyanate and iodide oxidation with 2, 6-dichloroquinone-4-chloro-imide: A novel and a new oxidizing agent. Oxid Commun 1998;21:369-75.

21. Nadh RV, Sundar BS, Radhakrishnamurti PS. Kinetics of oxidation of ethylamine, monoethanolamine and benzylamine by chloramine-T. Oxid Commun 2000;23:102-11.
22. Nadh RV, Sundar BS, Radhakrishnamurti PS. Kinetics of oxidation of iodide Ion by Ce (IV). Asian J Chem 1997;9:515-21.

23. Venkata Nadh R, Syama Sundar B, Radhakrishnamurti PS. Kinetics of oxidation of iodide by vanadium (V). J Indian Chem Soc 1999;76:75-8.

24. Szymanski JK, Temprano Coleto F, Perez Mercader J. Unusual kinetics of poly (ethylene glycol) oxidation with cerium (IV) ions in sulfuric acid medium and implications for copolymer synthesis. Phys Chem Chem Phys 2015;17:6713-7.

25. Nagarajan S, Srinivasan KS, Rao KV. Kinetic and mechanistic studies on the oxidation of poly (ethylene glycol) by ceric sulphate in sulphuric acid medium. Polym J 1994;26:851-7.

26. Chen X, Gao LJ, Gu F. Fenton oxidation of different molecular weights polyethylene glycols in wastewater. Adv Mater Res 2014;1033:382-6.

27. Prousek J, Duriskova I. Oxidative degradation of poly (ethylene glycol) $\mathrm{s}$ (PEG) by the fenton and photo-fenton reactions. Chemickelisty 1998;92:218-20.

28. Luo W, Zhu L, Wang N, Tang H, Cao M, She Y. Efficient removal of organic pollutants with magnetic nanoscaled $\mathrm{BiFeO}_{3}$ as a reusable heterogeneous fenton-like catalyst. Environ Sci Technol 2010;44:1786-91.

29. Imamura S, Nakamura M, Kawabata N, Yoshida J, Ishida S. Wet oxidation of poly (ethylene glycol) catalyzed by manganesecerium composite oxide. Ind Eng Chem Prod Res Dev 1986;25:34-7.

30. Lele BS, Kulkarni MG. Single step room temperature oxidation of poly (ethylene glycol) to poly (oxyethylene)-dicarboxylic acid. J Appl Polym Sci 1998;170:883-90.

31. Hassan R, Ibrahim S, Sayed S. Kinetics and mechanistic aspects on electron-transfer process for permanganate oxidation of poly (ethylene glycol) in aqueous acidic solutions in the presence and absence of Ru (III) catalyst. Int J Chem Kinet 2018;50:775-83.

32. Kumar YL, Nadh RV, Radhakrishnamurti PS. Kinetics of oxidation of myo-inositol by potassium periodate in alkaline medium. Asian J Chem 2012;24:5869-72.

33. Kumar YL, Nadh RV, Radhakrishnamurti PS. Substrate inhibition: oxidation of $\mathrm{d}$-sorbitol and d-mannitol by potassium periodate in alkaline medium. Russ J Phys Chem A 2014;88:774-8

34. Aveston J. Hydrolysis of potassium periodate: ultracentrifugation, potentiometric titration, and Raman spectra. J Chem Soc A 1969:273-5. Doi: 10.1039/j19690000273

35. Crouthamel CE, Hayes AM, Martin DS. Ionization and hydration equilibria of periodic acid. J Am Chem Soc 1951;173:82-7.

36. Tuwar SM, Nandibewoor ST, Raju JR. Oxidation of allyl alcohol by diperiodatonickelate (IV) in aqueous alkaline medium. J Indian Chem Soc 1992;69:651-3.

37. Shan JH, Li SM, Huo SY, Shen SG, Sun HW. Kinetics and mechanism of the oxidation of $\beta$-alanine by dihydroxydiperiodatoargentate (III) in an alkaline medium. J Iran Chem Soc 2005;2:226-31.

38. Kulkarni SD, Nandibewoor ST. A kinetic and 1 study on oxidation of Isoniazid drug by alkaline diperiodatocuprate (III)-A free radical intervention. Transition Met Chem 2006;31:1034-9.

39. Shan H, Wang HY, Song CY, Wang F. Kinetics and mechanism of oxidation of 2-Aminoethanol and 3-Amino-1-propanol by diperiodatoargentate (III) in alkaline medium. J Iran Chem Soc 2009;6:393-8.

40. Wynne Jones WF, Eyring $\mathrm{H}$. The absolute rate of reactions in condensed phases. J Chem Phys 1935;5:492-502.

41. http://msdssearch.dow.com/PublishedLiteratureDOWCOM/d h_0887/0901b80380887904.pdf [Last accessed on 10 May 2019]

42. Feigl F. Spot tests in organic analysis, elsevier publishing co., New York; 1956. p. 208.

43. Henning T. Polyethylene glycols (PEGs), the pharmaceutical industry. SOFW-J 2001;127:28-32.

44. Shanmugam AN, Subhapradha NA, Suman S, Ramasamy P, Saravanan $\mathrm{R}$, Shanmugam $\mathrm{V}$, et al. Characterization of 
biopolymer "chitosan" from the shell of donacid clam donax scortum (linnaeus, 1758) and its antioxidant activity. Int J Pharm Pharm Sci 2012;4:460-5.

45. Sailaja AK, Amareshwar P, Chakravarty P. Different techniques used for the preparation of nanoparticles using natural polymers and their application. Int I Pharm Pharm Sci 2011;3:45-50.

46. Mishra RK, Banthia AK, Majeed AB. Pectin based formulations for biomedical applications: a review. Asian J Pharm Clin Res 2012;5:1-7. 